\title{
Penambahan Alat Bantu Pemindah Produk Menggunakan Pneumatik dan Karakuri pada Mesin Cup Lower Pump Wire Press PT. Mitsuba Indonesia
}

\author{
Wahyu Isti Nugroho*, Muhammad Rienaldy Karuana, Timotius Anggit Kristiawan \\ Program Studi Sarjana Terapan Teknik Mesin Produksi dan Perawatan \\ Jurusan Teknik Mesin Politeknik Negeri Semarang \\ Jl. Prof. H. Soedarto, S.H., Tembalang, Kota Semarang, Jawa Tengah 50275 \\ *E-mail: wahyu.istinugroho@polines.ac.id
}

Diterima: 11-03-2021; Direvisi: 29-03-2021; Dipublikasi: 27-04-2021

\begin{abstract}
Abstrak
Pemindahan produk dari mesin press memiliki resiko yang sangat tinggi terhadap keselamatan operator. Salah satu mesin yang terdapat di PT Mitsuba Indonesia adalah Press Fit Pump Assy yang berfungsi untuk menyatukan lower cup dan upper cup module fuel pump. Permasalahan yang terjadi yaitu kapasitas produksi belum tercapai. Penyebabnya adalah ruang di dalam mesin yang cukup sempit, sehingga gerakan operator kurang leluasa dan perlu waktu pada saat pengambilan produk. Solusi untuk mengatasi masalah tersebut yaitu melakukan modifikasi pada mesin Cup Lower Pump Wire Press dengan menambahkan alat bantu pemindah produk. Tujuan dari penelitian ini mengetahui performansi dari modifikasi mesin Cup Lower Pump Wire Press. Metode penelitian yang digunakan yaitu metode RCA (Root Cause Analysis) yang meliputi identifikasi masalah, penentuan masalah, pemahaman masalah, identifikasi faktor penyebab, tindakan korektif, dan pemantauan system. Pengujian yang dilakukan adalah pengukuran waktu proses mesin Cup Lower Pump Wire Press sebelum dimodifiksi dan setelah dilakukan modifikasi. Hasil dari penelitian ini adalah lama waktu proses mesin Cup Lower Pump Wire Press yang sebelumnya rata-rata 10.10 detik dapat berkurang menjadi 8.99 detik atau berkurang sebesar $10,99 \%$.
\end{abstract}

Kata kunci: karakuri; pemindah produk; pneumatik

\begin{abstract}
transfer of product from the press machine a very high risk to operator. One of the machines available at PT Mitsuba Indonesia is the Press Fit Pump Assy which functions to assembly the lower cup and upper cup module of the fuel pump. This machine has been improved and renamed to Cup Lower Pump Wire Press. Cup Lower Pump Wire Press machine still had deficiencies and cause problems. The problem that occurs is that the production capacity has not been reached. The reason is that the space inside the machine is quite narrow so that the operator's movement are less flexible and it takes time when taking the product, resulting in a long cycle time. The solution to this problem is to modify the Cup Lower Pump Wire Press machine by adding a product transfer tool. The purpose of this research is to reduce the cycle time in the production process of the Lower Pump Wire Press Cup machine. The test carried out is the measurement of the process time of the Cup Lower Pump Wire Press machine before modification and after modification. The result of this research is that the processing time for the Cup Lower Pump Wire Press machine, which previously was an average of 10.10 seconds, can be reduced to 8.99 seconds or reduced by $10.99 \%$.
\end{abstract}

Keywords: karakuri; product transfer; pneumatic

\section{Pendahuluan}

Proses pengambilan produk dari mesin secara manual menggunakan tangan operator memiliki resiko keselamatan kerja yang tinggi. Proses pengambilan produk pada mesin cup lower pump wire press di PT Mitsuba Indoensia masih dilakukan secara manual yaitu mengambil produk yang sudah dilakukan proses press menggunakan tangan. Proses pengambilan produk secara manual selain beresiko terhadap keselamatan kerja operator juga mengakibatkan cycle time menjadi tinggi dan tidak konsisten, sehingga target produksi tidak terukur. Upaya mengurangi cycle time dilakukan dengan melakukan modifikasi penambahan alat pemindah produk pada mesin, sehingga cycle time dapat ditekan dan konsisten. Modifikasi suatu alat bantu perlu dilakukan penentuan desain, ukuran atau spesifikasi komponen yang dibutuhkan melalui perhitungan dan analisa, penentuan proses pembuatan atau pemilihan komponen [1]. 
Wahyu Isti Nugroho dkk /Jurnal Rekayasa Mesin

p-ISSN: 1411-6863, e-ISSN: 2540-7678

Vol.16|No.1|56-61|April|2021

Pertimbangan desain tersebut dilakukan supaya spesifikasi alat yang dibuat sesuai dengan kebutuhan [2]. Modifikasi yang dilakukan menggunakan mekanisme pneumatik dan karakuri. Sistem penumatik pada penerapannya banyak digunakan untuk sistem otomasi di industri modern, mulai dari proses pencetakan, pengaturan arah benda kerja, penyusunan, pencengkraman, pemindahan, sampai transfer produk [3]. Sistem pneumatik menggunakan udara yang bertekanan sebagai sumber energi yang dihasilkan oleh Air Compressor [4]. Sistem pneumatik memiliki keunggulan seperti kecepatan yang cukup tinggi, keandalan, biaya rendah, perakitan mudah, perawatan mudah dan ketersediaan udara terkompresi dihampir semua instalasi industri [5]. Salah satu komponen dari pneumatik adalah aktuator. Aktuator pneumatik adalah perangkat yang digunakan untuk mengubah tekanan udara menjadi energi mekanik untuk melakukan kerja. Aktuator digunakan untuk melakukan kerja yang diperlukan pada akhir langkah atau digunakan untuk membuat perpindahan oleh gerakan piston [6].

Karakuri merupakan konsep pemindahan barang yang diterapkan di industri Jepang dengan memanfaatkan bidang miring. Bidang miring merupakan salah satu pesawat sederhana yang sering dimanfaatkan manusia dalam menjalankan aktivitasnya [7]. Bidang miring sering digunakan dalam penerapan Hukum Newton [8]. Alasan digunakannya bidang miring sebagai media konkret yakni balok yang diletakkan pada bidang miring tidak perlu ditarik atau didorong untuk memberi gaya pada balok tersebut tetapi hanya dengan mengkondisikan bidang miring pada sudut tertentu maka akan ada gaya dorong secara alami [9]. Konsep ini umumnya dimanfaatkan untuk meringankan beban atau pekerjaan supaya tidak membutuhkan gaya yang begitu besar [10]. Penerapan karakuri ini dipadukan dengan penggunaan jig supaya produk yang dibawa tetap pada posisi yang ditentukan. Jig adalah alat bantu yang dirancang untuk memegang, menempatkan, dan menopang benda kerja serta mengarahkan alat selama mesin beroperasi [11]. Diperlukan penelitian pembuatan alat bantu pemindah produk pada mesin Cup Lower Pump Wire Press dengan menerapkan mekanisme pneumatik dipadukan dengan prinsip karakuri supaya dapat menghasilkan alat pemindah produk dengan waktu yang terukur dan konsisten namun tetap meminimalkan penggunaan daya untuk menghasilkan gaya pemindah produk.

Tujuan dari penelitian ini adalah mengetahui performansi dari modifikasi mesin Cup Lower Pump Wire Press dengan menambahkan sistem pneumatik dan karakuri pada desain mesin tersebut, serta melakukan pengujian cycle time sebelum dan sesudah dilakukan modifikasi.

\section{Material dan metodologi}

\subsection{Desain Transfer Unit Assy dan Karakuri Unit Assy}

Desain alat Transfer Unit Assy dan Karakuri Unit Assy menggunakan software Solidwork 2016 disajikan pada Gambar 1.

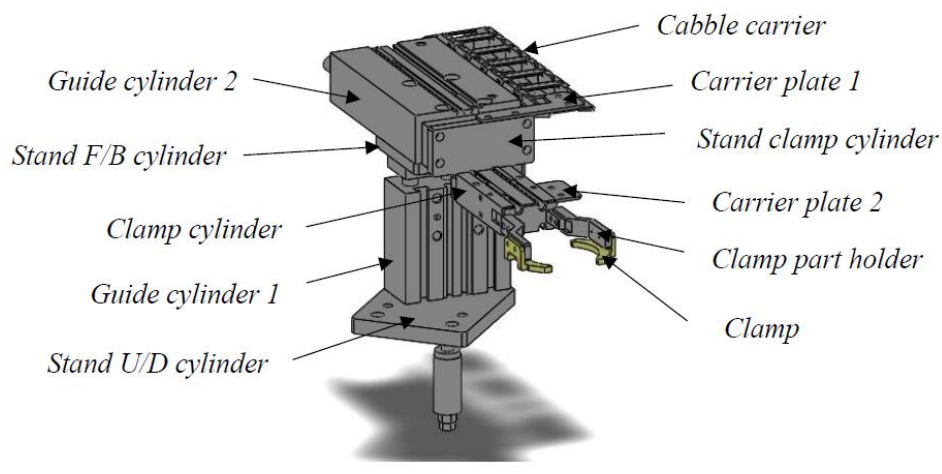

(a)

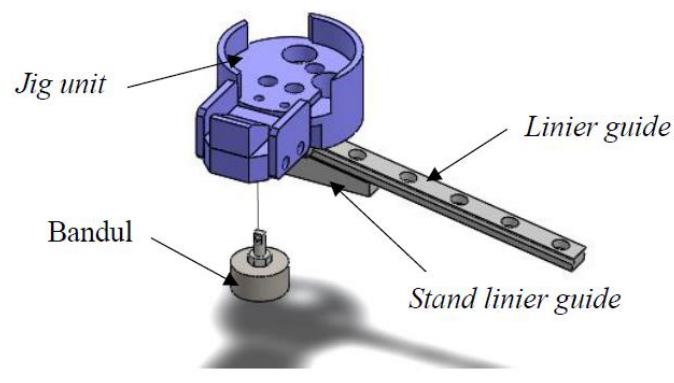

(b)

Gambar 1. Desain (a) Transfer Unit Assy dan (b) Karakuri Unit Assy (kanan) 
Wahyu Isti Nugroho dkk /Jurnal Rekayasa Mesin

p-ISSN: 1411-6863, e-ISSN: 2540-7678

Vol.16|No.1|56-61|April|2021

Desain penambahan transfer unit assy dan karakuri unit assy pada mesin Cup Lower Pump Wire Press disajikan pada Gambar 2. Prinsip kerja penambahan alat ini adalah untuk mengambil produk menggunakan gripper pada transfer unit kemudian dipindahkan dan diletakkan pada karakuri unit assy. Sehingga, benda kerja meluncur menuju tempat penampungan produk.

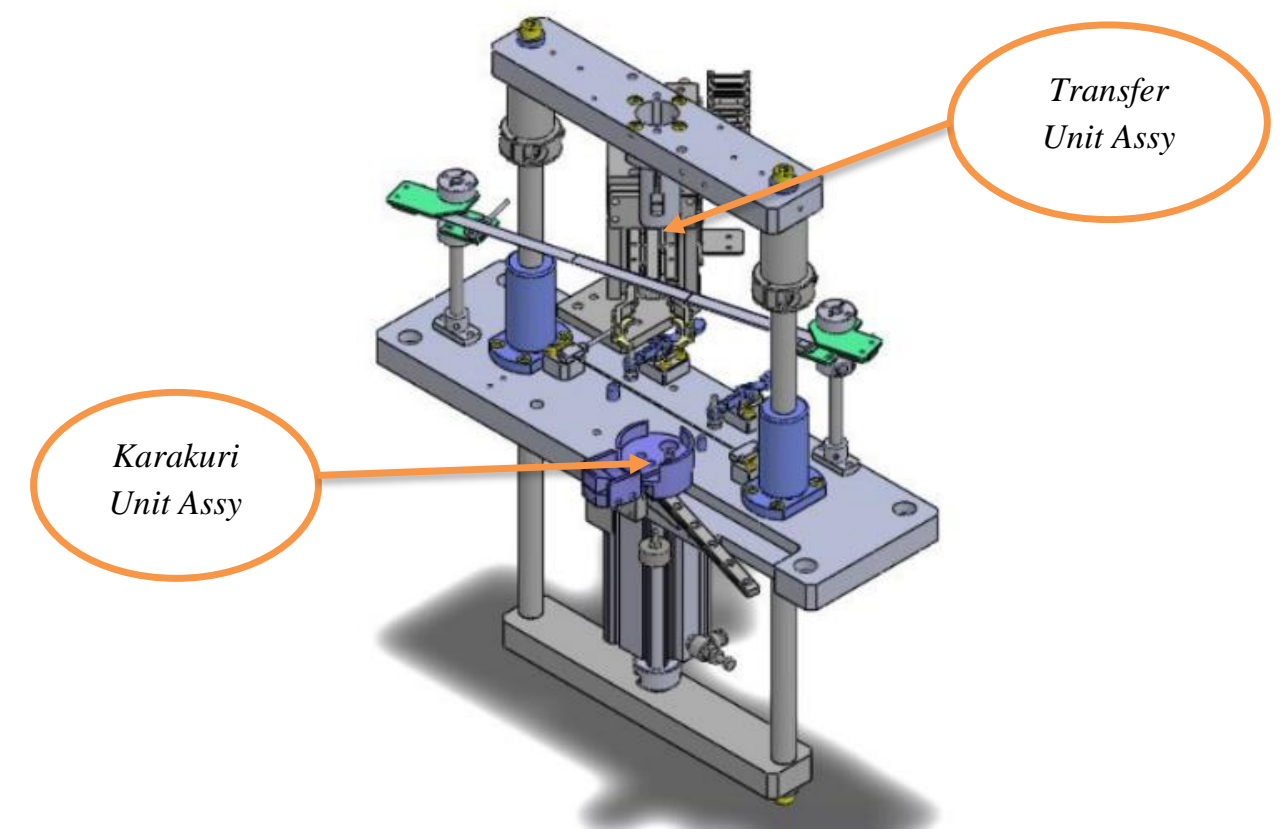

Gambar 2. Desain penambahan Transfer Unit dan Karakuri Unit Assy pada mesin Cup Lower Pump Wire Press

\subsection{Kebutuhan Silinder Pneumatik}

Terdapat satu jenis silinder pneumatik pada rancangan alat bantu pemindah produk. Perhitungan spesifikasi silinder pneumatik berdasarkan beban total obyek yang akan didorong [12]. Beban yang diterima silinder pneumatik terdiri dari beberapa beban komponen, diantaranya beban silinder pneumatik lainnya dan produk. Beban benda dapat diketahui melalui persamaan gaya $(\mathrm{F})$, massa $(\mathrm{m})$, dan gravitasi $(\mathrm{g})$.

$$
\mathrm{F}=\mathrm{m} \times \mathrm{g}
$$

Desain alat bantu pemindah produk menggunakan 2 buah guide cylinder dan 1 buah clamp cylinder. Beban terberat yang harus dikerjakan pneumatik ada pada guide cylinder 1 dimana terdapat 3 pembebanan komponen, yaitu guide cylinder 2 adalah $0,334 \mathrm{~kg}$, clamp cylinder $0,05 \mathrm{~kg}$, dan produk $0,16 \mathrm{~kg}$. berdasarkan persamaan 1 diperoleh gaya yang diperlukan untuk menerima beban total yaitu sebesar 5,33664 N. Output gaya yang dihasilkan diperoleh berdasarkan spesifikasi silinder pneumatik, besar kecilnya output gaya dipengaruhi oleh dimensi diameter silinder pada bore silinder pneumatik [13]. Perhitungan kebutuhan diameter silinder pneumatikvdengan persamaan gaya (F), tekanan kerja (P), dan luas penampang $(\mathrm{A})$.

$$
\mathrm{F}=\mathrm{P} \times \mathrm{A}
$$

Berdasarkan persamaan 2 diperoleh dimensi diameter silinder minimal yaitu sebesar 11,6 mm yang dibutuhkan untuk mendorong beban sebesar 5,33664 N. Jarak langkah (stroke) yang dibutuhkan sesuai dengan panjang untuk mengangkat produk dari jig mesin yaitu sebesar $25 \mathrm{~mm}$, sehingga spesifikasi silinder pneumatik yang dibutuhkan diantaranya adalah memiliki diameter bore minimal $11,6 \mathrm{~mm}$ dan panjang stroke $25 \mathrm{~mm}$. Setelah didapatkan spesifikasi 
Wahyu Isti Nugroho dkk /Jurnal Rekayasa Mesin

p-ISSN: 1411-6863, e-ISSN: 2540-7678

Vol.16|No.1|56-61|April|2021

silinder pneumatik yang cocok, digunakanlah silinder pneumatik dengan spesifikasi panjang stroke $25 \mathrm{~mm}$ dan diameter bore $12 \mathrm{~mm}$ tipe SMC MGPM12 $25 \mathrm{Z}$.

\subsection{Kemiringan Sudut Karakuri}

Karakuri merupakan sub assembly dari alat bantu pemindah produk. Karakuri harus dibuat dengan sudut kemiringan yang sesuai supaya tidak terlalu lambat ataupun tidak terlalu cepat dalam melakukan pemindahan produk. Sistem karakuri yang digunakan adalah linier guide, sehingga gaya gesek yang terjadi diabaikan karena 2 permukaan yang saling bersentuhan berupa bola-bola kecil. Rumus yang digunakan merupakan rumus Hukum Newton I untuk menentukan sudut kemiringan dimana benda tepat akan bergerak [14].

$$
\operatorname{Sin} \theta=\frac{W 2}{W 1}=\frac{m 2}{m 1}
$$

Perhitungan kemiringan karakuri menggunakan massa bandul m2 yaitu 25 gram dan massa jig m1 yaitu 146 gram. Berdasarkan persamaan 3 diperoleh sudut kemiringan minimal karakuri yang dibutuhkah pada saat tepat akan bergerak yaitu sebesar $9,85^{\circ}$, sehingga ditetapkan sudut kemiringan yang dibuat adalah $10^{\circ}$. Berdasarkan persamaan 4 yang merupakan rumus dasar hukum Newton II, maka dapat diketahui apakah karakuri akan bergerak dengan melihat percepatan yang terjadi [15].

$\left(\mathrm{W}_{1} \times \operatorname{Sin} \theta\right)-\mathrm{W}_{2}=\left(\mathrm{m}_{2}+\mathrm{m}_{1}\right) \times \mathrm{a}$

Diketahui $\mathrm{W}_{1}$ adalah penjumlahan beban jig karakuri dan beban produk 3,001 N, $\mathrm{W}_{2}$ adalah beban bandul 0,24525 $\mathrm{N}, \mathrm{m}_{1}$ adalah penjumlahan massa jig karakuri dan massa produk $0,306 \mathrm{~kg}, \mathrm{~m}_{2}$ adalah massa bandul 0,025 kg. Percepatan jig karakuri meluncur bersama produk dari kemiringan sudut karakuri $10^{\circ}$ adalah sebesar $0,8 \mathrm{~m} / \mathrm{s}^{2}$. Hal ini berarti terdapat percepatan yang mengakibatkan karakuri bergerak turun ketika terdapat produk diatasnya. Sehingga, dapat disimpulkan bahwa mekanisme karakuri dengan sudut kemiringan sebesar $10^{\circ}$ dapat digunakan pada rancangan alat bantu pemindah produk.

\subsection{Pembuatan alat}

Komponen pada Transfer Unit dan Karakuri yang dibuat semuanya produk standar atau sudah tersedia di pasaran, sehingga dalam pemilihan material perlu adanya pengetahuan tentang standar komponen yang dibutuhkan agar dalam proses pemilihan kebutuhan komponen dapat dilakukan sesuai spesifikasi. Pemilihan spesifikasi komponen pneumatik dilakukan dengan menghitung ukuran silinder terhadap gaya yang dibutuhkan alat supaya bekerja dengan baik.

\subsection{Pengujian Cycle Time}

Pengujian cycle time dilakukan dengan menghitung waktu pemindahan produk secara manual dibandingkan dengan penambahan alat Transfer Unit dan Karakuri Unit assy pada Cup Lower Pump Wire Press.

\section{Hasil dan pembahasan}

\subsection{Spesifikasi Alat}

Berdasarkan hasil perancangan dan perhitungan, dapat ditentukan spesifikasi alat bantu pemindah produk, sesuai Tabel 1. Berdasarkan data Tabel 2, diperoleh waktu pengambilan produk sebelum dilakukan modifikasi yaitu minimal sebesar 9.37 detik, maksimal sebesar 10.89 detik, dan waktu rata - rata sebesar 10.10 detik. 
Wahyu Isti Nugroho dkk /Jurnal Rekayasa Mesin

p-ISSN: 1411-6863, e-ISSN: 2540-7678

Vol.16|No.1|56-61|April|2021

Tabel 1. spesifikasi alat bantu pemindah produk

\begin{tabular}{ll}
\hline & \multicolumn{1}{c}{ Transfer Unit Assy } \\
\hline Dimension & $: 206 \times 246 \times 179 \mathrm{~mm}$ \\
Clamp Cylinder & $: 180^{\circ}$ Angular Type SMC-MHY2-10D-M9BL (bore size 10mm) \\
Guide Cylinder & $:$ Compact Guide Type SMC-MGPM12-75Z-M9BL (bore size 12mm) \\
Cable Carrier & $:$ SS400 \\
Stand U/D Cylinder & $:$ SS400 \\
Stand F/B Cylinder & $:$ SS400 \\
Stand Clamp Cylinder & $:$ AISI 1045 \\
Clamp Part Holder & $:$ AISI 1045 \\
Clamp Right \& Left & $:$ SPCC \\
Carrier Plate & $:$ 137 $\times 79 \times 47$ mm \\
\hline & $:$ MISUMI-SSEBZ10-135 (rail length $135 \mathrm{~mm})$ \\
\hline Dimension & $:$ Nylon \\
Linier Guide & $:$ AISI $1045\left(\theta=10^{\circ}\right)$ \\
Jig Unit & $:$ AISI 1045 \\
Stand Linier Guide &
\end{tabular}

Tabel 2. Data Pemindahan Produk secara Manual

\begin{tabular}{cc|cc|cc}
\hline \multicolumn{2}{c|}{ Pengujian 1 } & \multicolumn{2}{c|}{ Pengujian 2 } & \multicolumn{2}{c}{ Pengujian 3 } \\
\hline No. Pengujian & Cycle Time [detik] & No. Pengujian & Cycle Time [detik] & No. Pengujian & Cycle Time [detik] \\
\hline 1 & 10.19 & 1 & 10.10 & 1 & 10.37 \\
2 & 10.89 & 2 & 10.33 & 2 & 10.65 \\
3 & 10.27 & 3 & 10.69 & 3 & 9.56 \\
4 & 10.72 & 4 & 9.40 & 5 & 9.13 \\
5 & 9.57 & 5 & 10.53 & 6 & 9.54 \\
6 & 9.51 & 7 & 9.66 & 7 & 10.05 \\
7 & 9.53 & 8 & 9.37 & 8 & 10.34 \\
8 & 10.58 & 9 & 9.98 & 9 & 10.51 \\
9 & 10.26 & 10 & 10.32 & 10 & 10.22 \\
10 & 10.12 & & &
\end{tabular}

Data pada Tabel 3 merupakan cycle time sesudah adanya modifikasi berupa alat bantu pemindah produk pada mesin cup lower pump wire press. Pengambilan data dilakukan pada shift 1 sebanyak 3 kali pengujian. Masing-masing pengujian dilakukan sebanyak 10 kali pengambilan data dicatat menggunakan stopwatch. Diperoleh data cycle time sesudah modifikasi minimal sebesar 8.67 detik, maksimal sebesar 9.33 detik, dan cycle time rata - rata sebesar 8.99 detik. Dengan Penambahan alat bantu pemindah produk mampu menghasilkan efisiensi waktu sebesar $112.34 \%$.

Tabel 3. Data Hasil Percobaan Pengujian Fungsi Pencekaman

\begin{tabular}{ll|ll|lc}
\hline \multicolumn{2}{c|}{ Pengujian 1 } & \multicolumn{2}{c|}{ Pengujian 2 } & \multicolumn{2}{c}{ Pengujian 3 } \\
\hline \multirow{2}{*}{ No. Pengujian } & Cycle Time [detik] & No. Pengujian & Cycle Time [detik] & No. Pengujian & Cycle Time [detik] \\
\hline 1 & 8.87 & 1 & 8.78 & 1 & 9.33 \\
2 & 8.92 & 3 & 9.03 & 2 & 8.83 \\
3 & 8.96 & 4 & 9.15 & 3 & 9.27 \\
4 & 9.17 & 5 & 8.67 & 4 & 8.67 \\
5 & 8.98 & 6 & 9.91 & 5 & 8.99 \\
6 & 9.02 & 8 & 8.84 & 7 & 8.73 \\
7 & 9.24 & 9 & 9.07 & 8 & 8.82 \\
8 & 9.11 & 10 & 8.82 & 9 & 9.17 \\
9 & 8.68 & 8.97 & 10 & 9.02 \\
\hline
\end{tabular}


Wahyu Isti Nugroho dkk /Jurnal Rekayasa Mesin

p-ISSN: 1411-6863, e-ISSN: 2540-7678

Vol.16|No.1|56-61|April|2021

\section{Kesimpulan}

Upaya peningkatan kapasitas produksi dilakukan dengan mengurangi cycle time melalui modifikasi mesin cup lower press pump wire press dengan penambahan Transfer Unit dan Karakuri Unit Assy. Pengujian dilakukan sebanyak 30 kali. Diperoleh hasil pengujian sebelum dilakukan modifikasi dengan catatan waktu 10.10 detik, sedangkan hasil setelah dilakukan modifikasi dengan catatan waktu 8.99 detik. Berdasarkan data tersebut diperoleh penurunan cycle time 1.10 detik atau 10,99\% dari proses pemindahan produk secara manual.

\section{Daftar Pustaka}

[1] Nisbett, J. K. \& Budynas, R. G., Shigley's Mechanical Engineering Design Ninth Edition. New York: McGrawHill series in mechanical engineering; 2011.

[2] Khurmi, R. \& Gupta, J., Machine Design. 1st ed. New Delhi: Eurasia Publishing House; 2005.

[3] Beater, Peter., Pneumatic Drives System Design, Modelling and Control. Berlin: Springer; 2007.

[4] Syahril, A. \& Hidayat, M. F., Perancangan Ulang Peralatan Pneumatik Berbasis Programmable Logic Control (PLC) Untuk Kegiatan Praktikum. Jurnal Konversi Energi dan Manufaktur, Volume 1. 2018.

[5] Azzi, A. et al., Experimental Study of Friction in Pneumatic Seals. Tribology International; 2019.

[6] Jagadeesha, T., Pneumatics Concepts, Designs, and Applications. India: Universities Press Private Limited; 2015.

[7] Astuti, I. A. D., Pengembangan Alat Eksperimen Penentuan Percepatan Gravitasi Bumi Berdasarkan Teori Bidang Miring Berbasis Microcomputer Based Laboratory (MBL). Faktor Exacta. 2016; 9(02).

[8] Masin, I. \& Riegr, T., Advanced Modelling of The Karakuri Mechanism. Albufeira: INEGI/FEUP; 2017.

[9] Raisch, A. \& Sawodny, O., Analysis and Optimal Sizing of Pneumatic Drive Systems for Handling Tasks. Mechatronics, Volume 59. 2019.

[10] Setiawan, D., 2013. Penerapan Bidang Miring Untuk Mengetahui Konsepsi dan Keterampilan Proses Siswa SMK Terhadap Gaya Gesek. Fakultas Matematika Dan Ilmu Pengetahuan Alam Universitas Negeri Semarang; 2013.

[11] Fyona, A., Hakim, R. \& A., Desain Jig \& Fixture Untuk Break Shoes Sepeda Angin. Jurnal Teknologi dan Riset Terapan. 2019; 1(2).

[12] Sonera, A. L., Chauhan, D. B. \& Chaudhari, T. K., Design of Pneumatic Press for Bending and Punching Operation. Science and Technology. 2017; 3(3)

[13] Zein, R. M., Nugraha, R. A. \& Iqbal, M., Perancangan Produk Rasional Material Handling Equipment Pada Proses Manual Palleting Galon Air Mineral Untuk Mengurangi Beban Kerja Operator. e-Proceeding of Engineering; 2018. $5(3)$.

[14] Rahayu, A., S. \& M., Pengembangan Media Pembelajaran Hukum Newton Menggunakan Fotonovela Berbasis Kearifan Lokal. Semarang: Prodi S2 Pendidikan Fisika, PPs Universitas Negeri Semarang; 2015.

[15] Sirait, R., Pengaruh Massa Terhadap Kecepatan Dan Percepatan Berdasarkan Hukum II Newton Menggunakan Linier Air Track. Jurnal Ilmu Fisika dan Teknologi. 2018; 2. 